\title{
Funding a more equitable research community
}

\author{
Gemma Tracey talks to Nature Chemistry about ingrained inequalities in the research community and the role of \\ funders in replacing privilege with equitable and transparent systems.
}

\begin{abstract}
Your current role is 'Science and Research Lead - Diversity \& Inclusion' at the Wellcome Trust; what does this entail?

I am part of Wellcome's Diversity and Inclusion (D\&I) team, established back in 2017. We have three key D\&I goals: addressing inequalities as an employer and as a grant funder, as well as inclusive research design. My role focuses on the second of these goals: Wellcome's role as a funder. Wellcome funds a broad range of work related to human health - science, humanities and social science, and public engagement. Like many other funders, there are inequalities in our portfolio, notably in relation to disability, race and ethnicity, and also gender at higher career stages. I collaborate with colleagues to ensure our funding processes and policies are as inclusive as possible. I provide feedback and input to grant holders who have specific queries about how to lead in an inclusive way and I am currently working to identify how we can proactively address the barriers faced by people from certain backgrounds.
\end{abstract}

Can you tell us about your career path? I will confess that being asked this question often causes me to panic a little. I think there are two reasons behind this. Firstly, the term 'career path' feels, if not linear, most certainly determined - it suggests that there is a plan! Whereas that is not how I view my own working life. I would probably describe it more as a meandering - sometimes overgrown - footpath, destination still to be defined.

Secondly, like many people, I deal with impostor syndrome. Because I have studied and worked in the area of gender equality I was slow to accept the real impact of impostor syndrome on my day-to-day working life and overall career trajectory. It is as if I thought that because I knew and understood the concept, and its gendered manifestation, I was somehow immune! Any concerns that I had about my performance or confidence to take on a challenging project felt true and real. It has taken the considerate coaxing of line managers, mentors and friends to get me to see that my perception of my own abilities may be off-kilter.

I note these things because I find many profiles and interviews display a positive

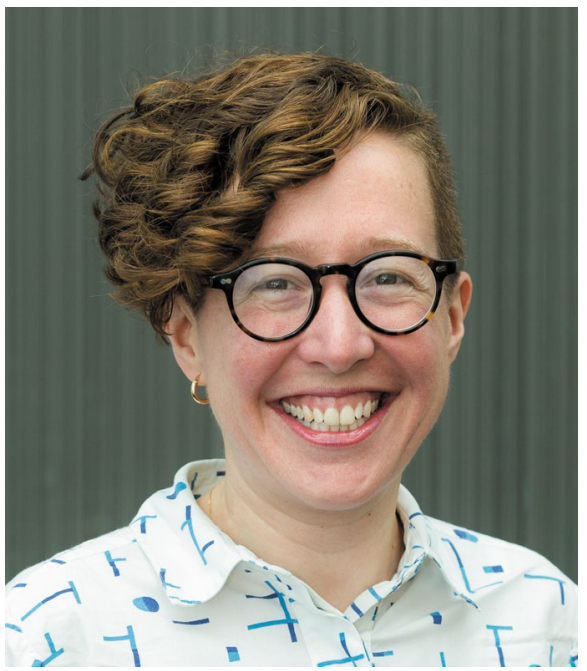

and was not, effective about this structural approach - I could discuss what we can learn about state socialist approaches to equality for hours.

Ultimately, these questions led to my interest in diversity in the STEM sector specifically. I worked on the STEM Ambassadors programme, then for the Equality Challenge Unit organization (best known for its work on the Athena SWAN programme) before joining Wellcome in 2017.

Can you tell us about the role of the Wellcome Trust, particularly pertaining to systemic racism?

In relation to systemic racism there are, from my perspective, three key roles for Wellcome - and therefore three key areas where Wellcome needs to play a role in addressing systemic racism. Firstly, we are an employer. Our data shows that staff of colour are underrepresented, particularly at more senior levels in the organization, and face specific barriers and moments of exclusion in comparison to their white colleagues.

Secondly, alongside other research funders and universities, Wellcome has important work to do to address the underrepresentation of marginalized scientists - specifically Black British researchers - in our grant-funding portfolio.

Thirdly, it is important that the research we fund and commission is inclusive in its design and practice. Despite all the great advances that science has brought, there is also a long and shameful history of racism in science; the Tuskegee Syphilis Study and the use of Henrietta Lack's cells are perhaps just two of the most infamous examples. I also think COVID-19 and last year's Black Lives Matter protests have thrown into starker relief the ways that racism pervades our societies, including educational and research spaces. Once one knows about racism in the scientific and medical fields, it is not at all surprising that there are lower levels of vaccine uptake amongst some communities, for example. So I think Wellcome - and all research funders have a role in supporting the design of more inclusive approaches to research, because it will make the research better and because it will hopefully increase trust in science and health interventions. 
Last year, Wellcome made a number of anti-racism commitments (https://wellcome. org/press-release/our-commitment-tacklingracism-wellcome). Since then, colleagues on my team have been leading a programme of work to ensure that our organization follows-through on these commitments (https://wellcome.org/what-we-do/ourwork/anti-racism-expert-group). They are specifically designing anti-racism principles that the organization will adopt, and an anti-racism toolkit that will support staff to integrate anti-racism into their work, whether they work in HR, lead our grant funding activities, or are involved in policy work. As part of this work my colleagues have recruited an external anti-racism advisory group - these individuals bring a great deal of expertise from different organizations and settings. We also have an internal staff advisory group, ensuring that people of colour who work at Wellcome have a leading voice in this work.

How would you describe the current culture in the scientific communities you interact with? For example, do you find that most people you meet acknowledge the issues of systemic racism and want to act but don't really know how? Or do you find that the majority of people in scientific communities believe the system is a meritocracy that works (mostly) as it should?

I find that people do acknowledge there are imbalances in funding, but not everyone agrees on what the root causes of these are. The scientists I meet are very proud of their work and the contribution it makes, both to knowledge generally and human health specifically, and there is no question that there have been some incredible scientific breakthroughs and discoveries. But I think this can also lead to some people being defensive when scientific institutions are challenged and criticized for being insufficiently diverse. They perhaps believe that they are fully objective in their decisions - and that the lack of diversity is the fault of our education system or broader inequalities in society.

I instead think that we all need to take responsibility for the part of the system where we are operating. It's not good enough to say, "I just didn't get a diverse group of applicants for this position" or "according to the criteria we have for $\mathrm{PhD}$ studentships, these people were the best candidates and unfortunately they happen to all be white." We need to see that the system is unfair and take active steps to address it.

There has been a subtle but important shift in the language used in my field of work - a field we might broadly call diversity and inclusion. Twenty years ago, people talked about "equal opportunities", the language then shifted to that of equality and diversity, and now we increasingly see the word equity being used. Equity is about equal outcomes, not just equal opportunities. When you start to look at the world through that lens you see how ingrained inequalities are, and the requirement for action at all education and career stages to bring about change.

For example, we know that there is an 'attainment' or 'degree-awarding' gap for students of colour in UK higher education. This means that these students are less likely to get first-class or upper-second-class honours degrees than their white counterparts, even if they entered university with similar grades. This means that these students may not be as competitive for $\mathrm{PhD}$ studentships. I would argue that the problem here lies in an education system that is disadvantaging them, so rather than expecting these students to change, we need to change the criteria and apply them with an anti-racism lens so that students from these backgrounds are on an equal footing for gaining access to postgraduate research, despite the barriers they have faced during their undergraduate studies.

In terms of advice for current scientists, including chemists, I think it's important to remember how opaque the research system is to outsiders. When I was in my early twenties my roommate who had just earned her undergraduate degree was working in a university. This enabled her to develop her expertise, build up her contacts and also to be a named author on some scientific papers. All of this together meant she was well-placed to apply for prestigious $\mathrm{PhD}$ programmes. I am in awe of her achievements and how she navigated a competitive and complex system, but at the same time, I am aware that many other promising students won't have known that these were steps that needed to be taken. Alongside this, many will have faced bias and prejudice, including during their studies and in applying for internships. The system is really stacked in favour of those who know the system (perhaps because of the university they attended for undergraduate studies, or because of knowing scientists in their family) - it's important that we take robust steps to offer those privileges to others. Or rather, remove the role of privilege and replace it with equitable and transparent systems.

There has recently been an increase in D\&l training across companies and academic departments. Why are such workshops not enough - and sometimes perhaps even not suitable - to tackle systemic inequalities?

I think this is a really good question and I like that you have asked "why are these workshops not sufficient", rather than the phrasing that I often see, such as "unconscious bias training doesn't work". I think the challenge is that people are often seeking the silver bullet, the one thing that will address the inequalities that exist, whether it be in recruitment, promotions or grant funding. It's this approach of seeking simple solutions that I would argue is part of the problem. Training needs to be one element of a broad programme of work. Training is about increasing knowledge and understanding, but once that knowledge and understanding has been gained, colleagues need to be given the time, resource and support from leadership to make changes to their ways of working to remove the barriers that exist. Here's an example: an individual working on health policy might complete training and through this gain a greater understanding of how bias and prejudice negatively impact disabled people in the workplace. But for them to address that they may need additional resources from their organization to adjust the working environment, or they may need to extend their project timelines to ensure that disabled people have enough time to provide input on a piece of policy work.

I sometimes fear that people think I am going to "make projects more complex and difficult", but I think we need to embrace this complexity, and we need to take enough time to do work in an inclusive manner. The work might be harder and take longer, but I also think it will be better work.

\section{Can you share some of the steps} being taken by the Wellcome Trust - both internally and externally - to remove barriers related to racism and other forms of discrimination?

I think the information I have shared above (about the programme of work on anti-racism) is the most relevant. This work is ongoing and we will be sharing updates on our progress externally in the months ahead. In terms of inclusive research design, a good example is the update that Wellcome made to its clinical trials policy last autumn (https://wellcome.org/grant-funding/ guidance/clinical-trials-policy). The updated policy requires researchers to engage with underserved communities in their efforts to recruit trial participants. It is important that the updated guidance encourages researchers to really engage with the idea that, for a healthcare intervention to be effective, it needs to be effective and safe for everyone, and that historically some groups 
have been underserved, which has negatively impacted health outcomes.

The creation of an equitable culture requires changes at all levels, from individuals to institutions. How can the Wellcome Trust help raise accountability? Accountability is one of the words that my colleagues and I regularly return to in our work. I think what we have seen in recent years is many organizations making vocal commitments to D\&I, but not necessarily holding themselves accountable when they have not met those commitments. What if organizations had key performance indicators (KPIs) related to the diversity of their workforce? Should all senior leaders have an objective related to D\&I included in their performance development review (PDR)?

Interviewed by Anne Pichon

Published online: 30 April 2021

https://doi.org/10.1038/s41557-021-00703-4 